\title{
Massive preexposure and preexposure in multiple contexts attenuate the context specificity of latent inhibition
}

\author{
DANIEL S. WHEELER, RAYMOND C. CHANG, and RALPH R. MILLER \\ State University of New York, Binghamton, New York
}

\begin{abstract}
Latent inhibition, which refers to attenuated responding to a conditioned stimulus (CS) after CSunconditioned stimulus (CS-US) pairings as a result of CS-alone presentations prior to the pairings, is often attenuated if preexposure and conditioning occur in different contexts (i.e., it is context specific). Here we report two conditioned lick suppression experiments, using rat subjects, that examined whether manipulations known to attenuate the context specificity of extinction could also eliminate the context specificity of latent inhibition. Context specificity of latent inhibition was eliminated when the CS was preexposed in multiple contexts (Experiment 1) and when the CS was massively preexposed in the training context alone (Experiment 2). These results and their practical implications are discussed in the framework of contemporary theories of latent inhibition.
\end{abstract}

Examination of the experimental design features of extinction and latent inhibition reveals fundamental similarities between these phenomena: Both preparations involve placing the subject on a partial reinforcement schedule in which the reinforced and nonreinforced trials are segregated into separate phases. The difference resides in the extinction effect occurring when a previously reinforced stimulus is presented repeatedly without reinforcement (Pavlov, 1927), and the latent inhibition effect occurring when a stimulus is first repeatedly presented without reinforcement and then is reinforced (Lubow \& Moore, 1959). Both of these schedules usually result in attenuated responding to the conditioned stimulus (CS) relative to a continuously reinforced control group.

More complex empirical similarities between latent inhibition and extinction become apparent in an examination of the effects of a long retention interval on these phenomena. Pavlov (1927) demonstrated that conditioned responding may be partially recovered after extinction treatment by imposing a long temporal interval between the nonreinforced presentations and the test of the CS (i.e., spontaneous recovery). Although not as ubiquitous, a similar effect has been seen in latent inhibition. There have been multiple reports suggesting that responding to a latently inhibited CS may be enhanced by interposing a re-

Support for this research was provided by NIMH Grant 33881. We thank Jim Esposito for his technical assistance, Jeff Amundson, Francisco Arcediano, Martha Escobar, Oskar Pineño, Steven Stout, and Kouji Urushihara for comments on an earlier version of the manuscript, and Kenia Castellanos for her assistance in the collection of the data. Correspondence should be addressed to R. R. Miller, Department of Psychology, SUNY-Binghamton, Binghamton, NY 13902-6000(e-mail: rmiller@binghamton.edu). tention interval between conditioning and test phases of the procedure (e.g., Aguado, Symonds, \& Hall, 1994; Killcross, Kiernan, Dwyer, \& Westbrook, 1998; Kraemer, Randall, \& Carbary, 1991; but see De la Casa \& Lubow, 2000, 2002).

In addition to their sensitivity to a retention interval, both the extinction and latent inhibition effects are context specific. The renewal effect is evidenced by an increase in responding to the target CS when it is presented in a context different from the one in which it was extinguished relative to responding in the same context in which the CS was extinguished (e.g., Bouton \& King, 1983). The effect may be seen either when testing occurs in the context in which the CS-US pairings occurred (e.g., Bouton \& Bolles, 1979) or in a new context (e.g., Bouton \& Bolles, 1979; Bouton \& Ricker, 1994). Across all renewal designs, the fundamental effect is an increase in responding when the CS is tested outside of the context in which extinction occurred.

The recovery of responding that constitutes the context specificity of latent inhibition is very similar to the renewal effect. Latent inhibition is considered context specific because the response attenuating effect of the unreinforced CS presentations often does not completely transfer to contexts outside of the preexposure context. This effect may be observed with training in a context other than the preexposure context (e.g., Hall \& Channell, 1983; Lovibond, Preston, \& Mackintosh, 1984; McLaren, Bennett, Plaisted, Aitken, \& Mackintosh, 1994). Thus, both latent inhibition and extinction may be attenuated if the testing context is different from the context in which the CS was presented without reinforcement. The observation that latent inhibition and extinction effects are empirically similar and vulnerable to similar changes as a result of contextual or temporal manipulations suggests that some common mechanisms may underlie the two effects. 
Although the preceding comparisons highlight the empirical similarities between extinction and latent inhibition, the two phenomena are generally theoretically dissociated. Associative accounts of latent inhibition often rely upon mechanisms such as CS-context associations (e.g., Grahame, Barnet, Gunther, \& Miller, 1994; Wagner, 1981) or an acquired attentional deficit (e.g., Lubow, Schnur, \& Rifkin, 1976; Pearce \& Hall, 1980) that retards acquisition. In contrast, extinction is often explained as unlearning of the CS-US association (Rescorla \& Wagner, 1972) or the building of an inhibitory association between the CS and the US (e.g., Pearce \& Hall, 1980; Wagner, 1981). Some theorists, although in the minority, have suggested that extinction and latent inhibition may result from similar mechanisms (e.g., Bouton, 1993). For instance, Miller's comparator hypothesis (e.g., Miller \& Matzel, 1988) assumes that latent inhibition and extinction both involve the building of an excitatory relationship between the context and the CS during nonreinforced trials. Because the comparator hypothesis predicts associative competition between the context and the CS in single-element conditioning, the conditioned responding to the CS should always vary inversely with the product of its association with the context and the context's association with the outcome. When a CS is preexposed, a strong CS-context association is formed before training, and it enhances the context's potential to serve as a competing cue when it is subsequently reinforced in compound with the CS (e.g., Grahame et al., 1994). The comparator hypothesis suggests that a similar mechanism operates during extinction, except the CS-context association is enhanced following training. Although it is likely that other factors are involved in the extinction of conditioned responding that do not affect latent inhibition, it is possible that both types of response attenuation share factors that are dependent on the association between the context and the CS. Such a claim suggests that manipulations affecting responding to an extinguished CS should have similar effects on responding to a preexposed CS, particularly if these manipulations affect the relationship between the CS and the context.

The present series of experiments was designed to further assess the empirical similarities between extinction and latent inhibition. Specifically, these experiments addressed the relationship between the renewal effect and the context specificity of latent inhibition. Both of these effects pose a challenge for behavioral therapists seeking to eliminate undesirable behaviors (e.g., extinction of phobias) or prevent maladaptive learning (e.g., latent inhibition of taste aversions caused by chemotherapy). If the effects of a particular treatment do not generalize to nonclinical environments, then the usefulness of the treatment is obviously reduced. It is therefore desirable to discover training manipulations that may enhance the generalization of both CS preexposure and extinction. Toward this end, behavioral experiments conducted in our laboratory have demonstrated that the renewal effect may be attenuated if the CS is massively extinguished(Denniston, Chang, $\&$ Miller, 2003) or if the CS is extinguished in multiple contexts (Gunther, Denniston, \& Miller, 1998). Although latent inhibition is often treated as being theoretically different from extinction, it is possible that these two manipulations (i.e., nonreinforced presentations of the CS in multiple contexts and massive nonreinforced CS exposure) could be used in a latent inhibition design to reduce the context specificity of the preexposure treatment. Two experiments involving CS preexposure were conducted to assess the effects that CS-alone presentations in multiple contexts and that massive CS-alone presentations might have on the context specificity of latent inhibition.

\section{EXPERIMENT 1 Preexposure in Multiple Contexts}

Experiment 1 was designed to investigate the effect of preexposure to a $\mathrm{CS}$ in multiple contexts on the context specificity of latent inhibition. If the context plays a role in latent inhibition similar to its role in extinction, then preexposing the CS in multiple contexts should enhance transfer of the latent inhibition effect to contexts other than those in which preexposure occurred. In this experiment, subjects in three latent inhibition groups (LI, LIshift, and M-Ctx; see Table 1) received 60 unreinforced presentations of CS X in Phase 1 and 4 reinforced presentations of CS X in Phase 2. Two control groups (Acq-D and $A c q-A B C)$ received unreinforced presentations of an

Table 1

Design Summary for Experiment 1

\begin{tabular}{lllllll}
\hline \multicolumn{1}{c}{ Group } & \multicolumn{3}{c}{ Phase 1 } & & Phase 2 & Test \\
\cline { 2 - 5 } \cline { 4 - 6 } 1. Acq-D & {$[---]_{\mathrm{A}}$} & {$[--]_{\mathrm{B}}$} & {$[--]_{\mathrm{C}}$} & {$[60 \mathrm{Y}-]_{\mathrm{D}}$} & {$[4 \mathrm{X} \rightarrow \mathrm{US}]_{\mathrm{D}}$} & {$[\mathrm{X}]_{\mathrm{E}}$} \\
2. LI & {$[--]_{\mathrm{A}}$} & {$[---]_{\mathrm{B}}$} & {$[--]_{\mathrm{C}}$} & {$[60 \mathrm{X}-]_{\mathrm{D}}$} & {$[4 \mathrm{X} \rightarrow \mathrm{US}]_{\mathrm{D}}$} & {$[\mathrm{X}]_{\mathrm{E}}$} \\
3. LI-Shift & $1 / 3 \mathrm{n}[60 \mathrm{X}-]_{\mathrm{A}}$ & $1 / 3 \mathrm{n}[60 \mathrm{X}-]_{\mathrm{B}}$ & $1 / 3 \mathrm{n}[60 \mathrm{X}-]_{\mathrm{C}}$ & {$[--]_{\mathrm{D}}$} & {$[4 \mathrm{X} \rightarrow \mathrm{US}]_{\mathrm{D}}$} & {$[\mathrm{X}]_{\mathrm{E}}$} \\
4. M-Ctx & {$[20 \mathrm{X}-]_{\mathrm{A}}$} & {$[20 \mathrm{X}-]_{\mathrm{B}}$} & {$[20 \mathrm{X}-]_{\mathrm{C}}$} & {$[---]_{\mathrm{D}}$} & {$[4 \mathrm{X} \rightarrow \mathrm{US}]_{\mathrm{D}}$} & {$[\mathrm{XX}]_{\mathrm{E}}$} \\
5. Acq-ABC & {$[20 \mathrm{Y}-]_{\mathrm{A}}$} & {$[20 \mathrm{Y}-]_{\mathrm{B}}$} & {$[20 \mathrm{Y}-]_{\mathrm{C}}$} & {$[---]_{\mathrm{D}}$} & {$[4 \mathrm{X} \rightarrow \mathrm{US}]_{\mathrm{D}}$} & {$[\mathrm{X}]_{\mathrm{E}}$} \\
\hline
\end{tabular}

Note- $\mathrm{Y}$ and $\mathrm{X}$ denote tone and white noise, counterbalanced within groups; $\rightarrow$ denotes "followed by"; US, 1-mA, 0.5-sec footshock; numbers $(4,20$, and 60$)$ next to the cues denote total trial numbers (over all days); subscripts A, B, C, D, and E denote five distinctly different contexts in which treatment occurred. Group names Acq-D and Acq-ABC denote acquisition control conditions that received either preexposure to a nontarget stimulus (Y) in Context D alone or in Contexts A, B, and C, respectively; Groups LI and LI-Shift indicate the conditions with preexposure to the target stimulus (X) either in the conditioning context (D) or in a nonconditioning context (one third of the subjects in A, one third in B, and one third in C, respectively); Group M-Ctx denotes preexposure of the target CS X in multiple contexts. All training occurred in Context D and all testing occurred in Context E. 
irrelevant stimulus $(\mathrm{Y})$ in Phase 1 followed by the reinforcement of CS X in Phase 2. The context of the CSpreexposure treatment was manipulated between groups. Groups Acq-D and LI received CS-preexposure treatment in the conditioning context, Group LI-Shift in one different context, and Groups M-Ctx and Acq-ABC in three different contexts. If the context-dependent recoveries from latent inhibition and extinction were similarly subject to change through the same manipulations, then we would expect to observe a latent inhibition effect when the context is not changed between phases (Group LI), recovery from latent inhibition when the context is singly shifted between phases (Group LI-Shift), and a disruption of that context specificity when preexposure occurs in multiple contexts (Group M-Ctx).

\section{Method}

\section{Subjects}

Thirty male (240-425 g) and 30 female (180-275 g) experimentally naive Sprague-Dawley descended rats bred in our colony served as subjects. Subjects were individually housed in wire-mesh cages in a vivarium maintained on a 16:8-h light:dark cycle. Experimental manipulations were conducted approximately midway through the cycle. A progressive water deprivation schedule was imposed over the week prior to the beginning of the experiment, until water availability was limited to 20 min per day. All the animals were handled three times per week for $30 \mathrm{sec}$, from time of weaning until the initiation of the study. The subjects were randomly assigned to one of the five previously mentioned groups, counterbalanced for sex ( $n=12$ per group): Acq-D, Acq-ABC, LI, LI-shift, and M-Ctx.

\section{Apparatus}

Five types of training enclosures were used as different contexts (R, V, S, MS, and MR). The five contexts (A, B, C, D, and E) were formed from $6 \mathrm{~V}$-shape $(\mathrm{V})$ enclosures, 6 rectangular $(\mathrm{R})$ enclosures, 12 square (S) enclosures, 12 modified square (MS) enclosures, and 12 modified rectangular (MR) enclosures. The R, V, and MS enclosures were designated as Contexts $\mathrm{A}, \mathrm{B}$, and $\mathrm{C}$ and were counterbalanced within groups; the $\mathrm{S}$ enclosures served as Context $\mathrm{D}$ (the training context), and finally, the MR enclosures served as Context $\mathrm{E}$ (the testing context).

The $\mathrm{R}$ enclosures were clear, Plexiglas rectangular chambers $22.75 \times 8.25 \times 13.0 \mathrm{~cm}(1 \times \mathrm{w} \times \mathrm{h})$ with a floor constructed of $0.48-\mathrm{cm}$ diameter rods spaced $1.5 \mathrm{~cm}$ center-to-center, connected by NE-2 neon bulbs that allowed constant-current footshock to be delivered by means of a high-voltage AC circuit in series with a 1.0$\mathrm{M} \Omega$ resistor. Each of the six $\mathrm{R}$ enclosures had its own environmental isolation chest. They were dimly illuminated by a $2-\mathrm{W}$ (nominal at $120 \mathrm{VAC}$ ) bulb driven at $60 \mathrm{VAC}$ mounted on an inside wall of the environmental isolation chest approximately $30 \mathrm{~cm}$ from the animal enclosure.

The $\mathrm{V}$ enclosures were $25.5-\mathrm{cm}$-long boxes in the shape of a vertical truncated-V $(28 \mathrm{~cm}$ high, $21 \mathrm{~cm}$ wide at the top, $5.25 \mathrm{~cm}$ wide at the bottom). The floor and sides were constructed of sheet metal. The ceiling was clear Plexiglas. The floor consisted of two parallel metal plates each $2 \mathrm{~cm}$ wide with a $1.25-\mathrm{cm}$ gap between them. The $\mathrm{V}$ enclosures were dimly illuminated by a 7-W (nominal at 120 VAC) bulb driven at $60 \mathrm{VAC}$ mounted on an inside wall of the environmental isolation chest approximately $30 \mathrm{~cm}$ from the animal enclosure, with the light entering the animal enclosure being primarily that reflected from the roof of the environmental chest. Due to differences in opaqueness of the enclosures, this level of illumination approximately matched that of the $\mathrm{R}$ enclosures.

The $\mathrm{S}$ enclosures (Context D) consisted of 12 operant chambers each measuring $30.5 \mathrm{~cm} \times 27.5 \mathrm{~cm} \times 27.3 \mathrm{~cm}(1 \times \mathrm{w} \times \mathrm{h})$. All chambers had clear Plexiglas ceilings and sidewalls, and metal front and back walls. Chamber floors were constructed with 4-mm grids spaced $1.7 \mathrm{~cm}$ apart center-to-center, connected with NE-2 neon bulbs that allowed constant-current footshock to be delivered by means of a high-voltage AC circuit in series with a 1.0-M $\Omega$ resistor. Each chamber was dimly illuminated by a dim (\#48PSB) houselight.

The MS enclosures were different instances of the $\mathrm{S}$ enclosures, with the addition of a Plexiglas floor plate, an odor cue, and the absence of the houselight. The odor cue was produced by two drops of banana odor on the surface of a wooden cube, which was placed inside the sound-attenuating environmental isolation chest, but not inside the animal chamber.

The MR enclosures (Context E) were different instances of the $R$ enclosures, with the addition of a Plexiglas floor plate, an odor cue, and the absence of the houselight. The odor used in the MR enclosures was produced by two drops of methyl salicylate (a mint odor) on the surface of a wooden cube. Each MR enclosure was equipped with a water-filled lick tube which, when installed, extended $1 \mathrm{~cm}$ into a cylindrical niche (axis perpendicular to a chamber wall) $4.5 \mathrm{~cm}$ in diameter, left-right centered with its bottom $1.75 \mathrm{~cm}$ above the floor of the apparatus, and $5.0 \mathrm{~cm}$ deep. An infrared beam $0.5 \mathrm{~cm}$ in front of the lick tube monitored when subjects were drinking.

In all of the aforementioned chambers, two $45-\Omega$ speakers mounted on different walls of the interior of each environmental chest could deliver a complex tone (consisting of $3000-\mathrm{Hz}$ and $3200-\mathrm{Hz}$ pure tones) or a white noise, both at $8 \mathrm{~dB}$ (C scale) above the ambient background, which served as CSs X and Y, counterbalanced within groups. The stimulus duration during preexposure and conditioning was $10 \mathrm{sec}$. Background noise (primarily from a ventilation fan) was $78 \mathrm{~dB}$ (C scale).

All treatment took place in Contexts A, B, C, and D, but testing of CS X took place only in Context E. Thus, the water-filled lick tubes were available only in Context E. A novel testing context was used to eliminate the possibility that the excitation of the conditioning context (D) might generalize to the test stimulus X. Also, testing in a novel context is more analogous to clinical applications than training and testing in the same context. Patients are often treated in a clinical setting and released into a different context. The effectiveness of an exposure therapy is frequently assessed by its potential to generalize to other contexts. Thus, testing in a different context has a clear practical rationale.

\section{Procedure}

Acclimation. On Day 1, all the groups were acclimated to Context $\mathrm{E}$ (the test context) for $30 \mathrm{~min}$ to establish baseline drinking. During this session, the animals had free access to the water-filled tubes and no nominal stimuli were presented.

CS preexposure (Phase 1). On Days 2-13, context-alone exposure or CS preexposure took place in Contexts A, B, C, and D (Table 1). On each day, there was one 60-min session for each subject. The CS-preexposure sessions occurred on Days 3, 7, and 12. During these sessions, subjects received 20 CS X-alone or CS Yalone presentations of $10 \mathrm{sec}$ depending on the treatment scheduled for their group. The mean intertrial interval (ITI; CS onset to CS onset) was $185 \mathrm{sec}$ (specifically 130, 150, 210, and $250 \mathrm{sec}$ ). The group to which the subject belonged determined the contexts in which the CS preexposure took place. For Groups Acq-D and LI, preexposure to CSs Y and X, respectively, took place in Context D (the training context). Furthermore, on Days 2, 4-6, 8-11, and 13, these groups received exposure to Contexts A, B, and C, which matched the context exposure of Groups LI-Shift, M-Ctx, and Acq$\mathrm{ABC}$. The order of context exposure was randomly distributed by days. The same matching of context exposure was implemented in the rest of the groups (across groups, CSs differed and were given in different locations). One third of the subjects in Group LI-Shift received preexposure to CS X exclusively in Context A, another one third in Context B, and the final third in Context C. Finally, Groups M-Ctx and Acq-ABC received preexposure to CS X and 
CS Y, respectively, distributed uniformly over Contexts A, B, and C. No lick tubes were present during this phase.

Conditioning (Phase 2). On Day 14, all of the subjects received four CS X $\rightarrow$ US pairings in Context D, during which the termination of the 10-sec CS X coincided with the onset of the US. The US was a 1.0-mA, 0.5 -sec footshock. Trial onset was at $4,18,30$, and $50 \mathrm{~min}$ into the single 60-min conditioning session, with a mean ITI of approximately $15 \mathrm{~min}$. No lick tubes were present.

Reacclimation. On Days 15 and 16, reacclimation took place in Context E for 30 min. During this session, the animals had free access to the water-filled tubes and no nominal stimuli were presented. The purpose of these reacclimation sessions was to stabilize baseline drinking, which is usually disrupted by footshock.

Testing. On Day 17, testing with CS X took place in Context E. After placement of the subjects in the testing context, the time required to complete the first 5 cumulative sec of licking was recorded (pre-CS score). (The first 5 cumulative sec of licking specifically refers to the cumulative time that the infrared beam immediately in front of the lick tube was broken.) Immediately following 5 cumulative sec of licking, CS X was presented for $15 \mathrm{~min}$, and the time it took the subject to complete 5 more cumulative sec of licking (now in the presence of the CS) was recorded as our critical dependent variable (CS score). Any subjects that took more than $60 \mathrm{sec}$ to complete the first 5 cumulative sec of licks were scheduled to be excluded from all the subsequent analyses because such high pre-CS scores indicated an unusually strong fear to the testing context. No subjects were excluded from the present study. All the drinking latencies (both prior CS and during CS presentation) were converted into $\log$ (base 10) times to better approximate the normality assumption of parametric tests. An $\alpha$ level of .05 was selected as our criterion for significance.

\section{Results and Discussion}

The present experiment showed that preexposing a stimulus in multiple contexts attenuated the context specificity of latent inhibition. Most importantly, attenuation of la- tent inhibition due to a context shift between preexposure and conditioning was not observed if the CS preexposure took place in three contexts (as opposed to one context) prior to the CS-US pairings in the training context. The following statistical analyses confirmed these observations.

Prior to the analyses of the CS suppression scores, an analysis of the pre-CS times to complete 5 cumulative sec of drinking was conducted to ensure that the baseline drinking prior to the target stimulus presentation was similar across groups. A one-way analysis of variance (ANOVA) conducted on the pre-CS scores revealed no significant difference between the groups $\left[F(4,55)=0.70, M S_{\mathrm{e}}=\right.$ $0.02, p>.50]$. Given similar pre-CS scores, any differences in the CS scores between the groups could be attributed to the subjects' conditioned fear response to the target stimulus. To ensure that the use of different physical contexts did not confound responding in Group LIShift (one third of the subjects each received CS preexposure in Contexts $\mathrm{A}, \mathrm{B}$, and $\mathrm{C}$, respectively), a one-way ANOVA was conducted on the CS scores of the subgroups (A, B, and C) of LI-shift. No subgroup differences were detected $\left[F_{\mathrm{S}}(1,9)<1\right]$. Because the subgroups were counterbalanced and did not significantly differ from one another, their data were pooled for all of the subsequent analyses.

A one-way ANOVA was then conducted on the times to complete 5 cumulative sec of drinking in the presence of the CS to assess possible treatment effects. Using group as an independentfactor and lick suppression in the presence of the target CS as the dependent factor, an overall effect was detected $\left[F(4,55)=23.17, M S_{\mathrm{e}}=0.05, p<.001\right]($ Figure 1). Using the error term from this one-way ANOVA,

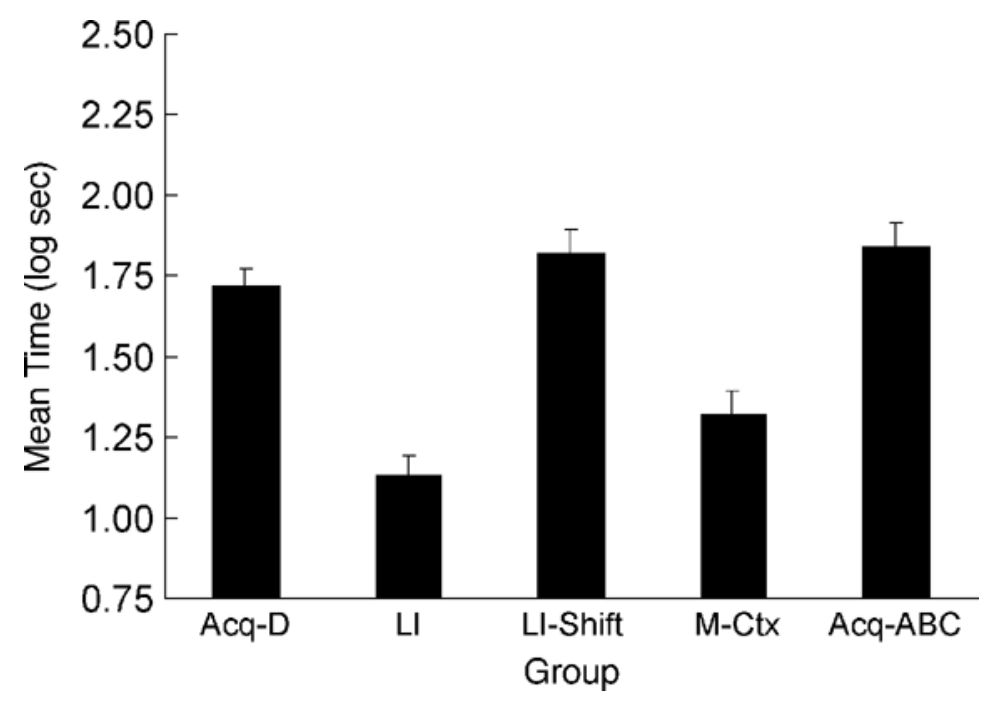

Figure 1. Experiment 1: Preexposure in multiple contexts. Bars depict mean times to complete 5 cumulative sec of drinking in the presence of the test stimulus $(X)$. Greater scores indicate greater fear, thus better conditioned responding. Therefore, lower scores are indicative of latent inhibition. Error brackets denote the standard error of the mean for each group. See Table 1 for procedural details. 
planned comparisons were conducted to investigate the specific treatment effects. A planned comparison of Groups Acq-D and LI revealed a latent inhibition effect $[F(1,55)=38.65, p<.001]$. The latent inhibition effect was not observed when the subjects received preexposure and conditioning in different contexts, and the means indicate there was not even a tendency toward latent inhibition (LI-shift vs. Acq-D) $[F(1,55)=1.25, p>.20]$. This attenuation of latent inhibition was less pronounced if the CS-preexposure training occurred in multiple contexts; a planned comparison of Groups M-Ctx and Acq-ABC demonstrated that latent inhibition was not abolished by training in a context different from the preexposure context when the CS-preexposure treatment took place in multiple contexts $[F(1,55)=30.02, p<.001]$. The observation that subjects in Group LI-Shift suppressed more to the target CS than did subjects in Group M-Ctx supports this conclusion $[F(1,55)=27.72, p<.001]$. The level of suppression exhibited in Group M-Ctx was, however, greater than that expressed by Group LI, suggesting that the effect of CS preexposure did not generalize perfectly, even when the CS was preexposed in multiple contexts $[F(1,55)=4.28, p<.05]$. These results demonstrate that although latent inhibition is sometimes limited to the preexposure context, the effect will be less context specific when multiple preexposure contexts are used.

\section{EXPERIMENT 2 Massive Preexposure}

Experiment 1 established that preexposing a CS in multiple contexts other than the training and testing contexts attenuated the context specificity of latent inhibition, thereby establishing a parallel with the previously observed reduction of the context specificity of extinction by extinction in multiple contexts (Gunther et al., 1998). Denniston et al. (2003) identified a second manipulation that also attenuated the context specificity of extinctionnamely, truly massive extinction of the CS (i.e., 800 nonreinforced trials). If the same manipulation can disrupt the context specificity of latent inhibition, then further empirical support would be garnered to suggest that latent inhibition and extinction share a common cognitive process regarding the role of context in responding. In order to in- vestigate the effect of massive CS preexposure, we conducted an experiment similar to Denniston et al.'s Experiment 2 , except that the nonreinforced trials occurred prior to the reinforced trials. We anticipated that a massive number of CS-preexposure trials would attenuate the context specificity of latent inhibition relative to few CSpreexposure trials.

This experiment was conducted in two separate replications. In the results of the first replication, we observed a nonsignificant tendency for massive CS preexposure to increase the context generality of latent inhibition. In order to test the reliability of this tendency, we conducted a complete replication. Before combining the data from the two replications, we determined that there was no significant main effect or interaction of replication with treatment $(p s>.30)$.

\section{Method}

\section{Subjects}

Sixty male $(228-325 \mathrm{~g})$ and 60 female $(180-241 \mathrm{~g})$ experimentally naive Sprague-Dawley descended rats bred in our colony served as subjects. Subjects were maintained, housed, and handled as in Experiment 1. The subjects were randomly assigned to one of five groups: Group Acq, Few-LI, Few-Shift, Many-LI, and ManyShift, counterbalanced for sex $(n=24$ per group; see Table 2).

\section{Apparatus}

CS preexposure and conditioning took place in two types of enclosures ( $\mathrm{R}$ and $\mathrm{V})$. Six of each type of enclosure served as Contexts A and B, counterbalanced within groups. The descriptions of the $\mathrm{R}$ and $\mathrm{V}$ enclosures are detailed in Experiment 1. A third context, $\mathrm{C}$, was used for testing for the same reason that a nontreatment context was used for testing in Experiment 1. Context $\mathrm{C}$ was provided by the MR enclosures used in Experiment 1 . Context $\mathrm{C}$ was also equipped with a water-filled lick tube as previously described. The CSs and US were the same as in Experiment 1. Contexts A and B were used in Phase 1 (CS-preexposure phase), Context B was also used in Phase 2 (conditioning), and Context $\mathrm{C}$ was used only in the acclimation, reacclimation, and testing phases.

\section{Procedure}

Acclimation. On Day 1, all the groups were acclimated to Context $\mathrm{C}$ for 30 min following the procedure described in Experiment 1 .

CS preexposure (Phase 1). On Days 2-17, context-alone exposure and CS-preexposure training took place in Contexts A and B. Each subject experienced one 60-min session per day. Exposure to Contexts $\mathrm{A}$ and $\mathrm{B}$ was arranged in the following fashion by days:

Table 2

Design Summary for Experiment 2

\begin{tabular}{|c|c|c|c|c|}
\hline Group & \multicolumn{2}{|c|}{ Phase 1} & \multirow{2}{*}{$\begin{array}{c}\text { Phase 2 } \\
{[4 \mathrm{X} \rightarrow \mathrm{USS}]_{\mathrm{B}}} \\
{[4 \mathrm{X} \rightarrow \mathrm{US}]_{\mathrm{B}}} \\
{[4 \mathrm{X} \rightarrow \mathrm{US}]_{\mathrm{B}}} \\
{[4 \mathrm{X} \rightarrow \mathrm{US}]_{\mathrm{B}}} \\
{[4 \mathrm{X} \rightarrow \mathrm{US}]_{\mathrm{B}}}\end{array}$} & \multirow[b]{2}{*}{$\begin{array}{l}\text { Test } \\
{[X]_{\mathrm{C}}} \\
{[\mathrm{X}]_{\mathrm{C}}} \\
{[\mathrm{X}]_{\mathrm{C}}} \\
{[\mathrm{X}]_{\mathrm{C}}} \\
{[\mathrm{X}]_{\mathrm{C}}}\end{array}$} \\
\hline $\begin{array}{l}\text { 1. Acq } \\
\text { 2. Few-LI } \\
\text { 3. Few-Shift } \\
\text { 4. Many-LI } \\
\text { 5. Many-Shift } \\
\end{array}$ & $\begin{array}{l}{[--]_{\mathrm{A}}} \\
{[---]_{\mathrm{A}}} \\
{[300 \mathrm{Y}-]_{\mathrm{A}} /[100 \mathrm{X}-]_{\mathrm{A}}} \\
{[---]_{\mathrm{A}}} \\
{[400 \mathrm{X}-]_{\mathrm{A}}}\end{array}$ & $\begin{array}{l}{[400 \mathrm{Y}-]_{\mathrm{B}}} \\
{[300 \mathrm{Y}-]_{\mathrm{B}} /[100 \mathrm{X}-]_{\mathrm{B}}} \\
{[---]_{\mathrm{B}}} \\
{[400 \mathrm{X}-]_{\mathrm{B}}} \\
{[---]_{\mathrm{B}}} \\
\end{array}$ & & \\
\hline $\begin{array}{l}\text { Note-Y and } \\
0.5 \text {-sec footsh } \\
\text { note three dist } \\
\text { and LI denote } \\
\text { (100) CS-pree }\end{array}$ & $\begin{array}{l}\text { lick and white noise, c } \\
\text { ers }(4,100,300 \text {, and } 4 \\
\text { rent contexts. Acq denc } \\
\text { oreexposure control; } m c \\
\text { ials; shift denotes conte } \\
\text { from the conditioning }\end{array}$ & $\begin{array}{l}\text { anced within groups; } \\
\text { to the cues denote tria } \\
\text { ntrol condition that re } \\
\text { tes extensive (400) Cs } \\
\text { ondition, in which CS }\end{array}$ & $\begin{array}{l}\text { s "followed } \\
\text {; subscripts } \\
\text { exposure to } \\
\text { sure trials; } \\
\text { ure training } \\
x+C\end{array}$ & $-\mathrm{mA}$, \\
\hline
\end{tabular}


ABBABAABABBABAAB. Therefore, all the groups experienced Context A on Days 2, 5, 7, 8, 10, 13, 15, and 16, and Context B on Days 3, 4, 6, 9, 11, 12, 14, and 17. The stimulus preexposure sessions included $10 \mathrm{CS}$-preexposure trials per $12 \mathrm{~min}$, and the same trial regimen was cycled five times to generate $50 \mathrm{CS} \mathrm{X}$ or Y presentations of $10 \mathrm{sec}$ each. The mean ITI for trial onset was $56 \mathrm{sec}$ (range = 30-84 sec; specifically, 50, 64, 43, 57, 84, 71, 80, 34, 60, 47, and $30 \mathrm{sec}$ ). The subjects' group determined which stimulus (X or Y) was preexposed in which context (A or B) on which days. Subjects in Groups Acq and Many-LI received 400 exposures to CS Y and CS X, respectively, in Context B (on Days 3, 4, 6, 9, 11, 12, 14, and 17). Subjects in the Many-Shift group received their $400 \mathrm{CS} X$ exposures in Context A (on Days 2, 5, 7, 8, 10, 13, 15, and 16). Subjects in the Few-LI group received 300 exposures to CS Y in Context B on Days 3, 4, 6, 9, 11, and 12, followed by 100 exposures to CS X in Context B on Days 14 and 17. Subjects in the Few-Shift group received 300 exposures to CS Y in Context A on Days 2, 5, 7, 8,10 , and 13, followed by 100 exposures to CS X in Context A on Days 15 and 16. Importantly, this procedure maintained a uniform mean ITI between groups for exposure to CS X.

Conditioning (Phase 2). On Day 18, all of the subjects received four CS X $\rightarrow$ US pairings in Context B, during which the termination of the 10-sec CS X coincided with the onset of the US. The trial onsets were at 4, 18, 30, and 50 min into the 60-min session (mean ITI was $15 \mathrm{~min}$, as in Experiment 1). No lick tubes were present during this phase.

Reacclimation. On Days 19 and 20, reacclimation took place in Context $\mathrm{C}$ for $30 \mathrm{~min}$, following the procedure described in Experiment 1 .

Testing. On Day 21, testing of CS X took place in Context C. The test procedure was the same as that used in Experiment 1. As in Experiment 1 , any subjects that took more than $60 \mathrm{sec}$ to complete the first 5 cumulative sec of drinking (pre-CS scores) were excluded from all the subsequent analyses. As a result of this rejection criterion, 1 subject from Group Few-Shift was excluded from the overall analyses.

\section{Results and Discussion}

The results of the present experiment show that the context specificity of latent inhibition is sensitive to the number of preexposure trials. Typically, it is found that the latent inhibition effect is disrupted when preexposure and conditioning take place in different contexts. However, the present findings indicate that this context specificity was not apparent when a large number of CS-preexposure trials (400) relative to few trials (100) were administered prior to conditioning pairings. The following statistical analyses support this conclusion.

Prior to the critical analyses conducted on lick suppression scores in the presence of the target CS X, a one-way ANOVA performed on the pre-CS scores indicated that all groups were drinking at similar baseline rates prior to the presentation of CS X $\left[F(4,114)=1.92, M S_{\mathrm{e}}=0.03, p>\right.$ .11]. Another one-way ANOVA indicated that all groups were drinking at similar baseline rates prior to the presentation of CS X. Another one-way ANOVA performed on the 5 cumulative sec of drinking in the presence of the target CS X (CS suppression scores) showed a main effect of treatment $\left[F(4,114)=26.30, M S_{\mathrm{e}}=0.14, p<.001\right]$. The means of each treatment group are shown in Figure 2.

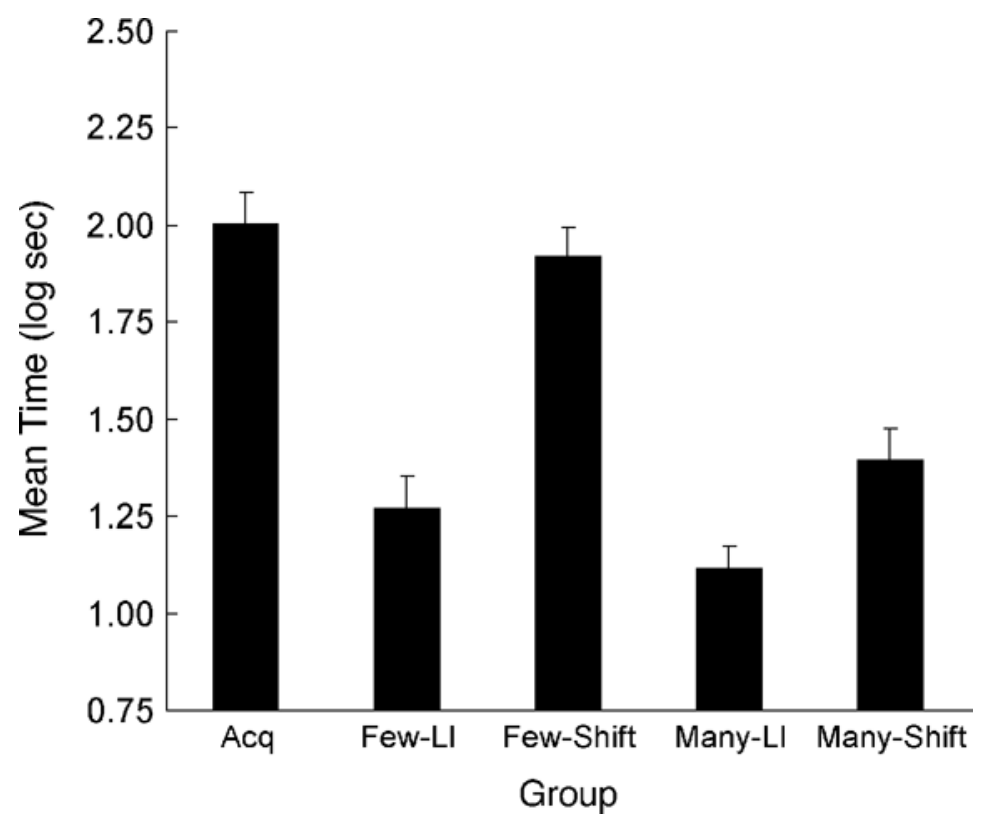

Figure 2. Experiment 2: Massive preexposure. Bars depict mean times to complete 5 cumulative sec of drinking in the presence of the test stimulus (X). Greater scores indicate greater fear, thus better conditioned responding. Therefore, lower scores are indicative of latent inhibition. Error brackets denote the standard error of the mean for each group. See Table 2 for procedural details. 
In order to understand the data pattern, planned comparisons were conducted on the drinking latency in the presence of the target CS X. A planned comparison of Groups Acq and Many-LI revealed the CS-preexposure (i.e., latent inhibition) effect, in which behavioral control by a CS is retarded due to pretraining exposure to that stimulus $[F(1,114)=65.98, p<.001]$. This latent inhibition was also apparent in Group Few-LI relative to Group Acq $[F(1,114)=45.59, p<.001]$. A comparison of Groups Many-Shift and Many-LI showed that greater conditioned suppression was observed when preexposure training took place in a context that differed from the conditioning context $[F(1,114)=6.56, p<.05]$. The renewal of responding was also observed in subjects receiving few preexposures, with Group Few-Shift suppressing more than Group Few-LI $[F(1,114)=34.95, p<.05]$.

Central to the present experiment was the question of whether massive CS-preexposure training would reduce the attenuation of latent inhibition that arises from differences between the preexposure context and the conditioning context. This was examined using a 2 (preexposure number: few vs. many) $\times 2$ (context: LI vs. shift) ANOVA, which did reveal an interaction between the number of preexposures given and the context of training $[F(1,91)=$ $\left.5.95, M S_{\mathrm{e}}=0.14, p<.05\right]$. We suspected that this interaction resulted from a larger renewal effect in the subjects in the few condition relative to the subjects in the many condition. This expectation was confirmed, as animals in Group Few-Shift suppressed drinking more to the target CS than did animals in Group Many-Shift $[F(1,91)=$ 23.10, $p<.001]$. Also, a comparison of Groups Few-LI and Many-LI showed no significant difference in the level of latent inhibition produced by the different amounts of preexposure $[F(1,91)=1.94, p>.15]$. This suggests that, at least in this preparation, the $100 \mathrm{CS}$ preexposures given to Group Few-LI produced a level of latent inhibition that was not significantly different from that produced by 400 CS preexposures. One possible problem with this comparison is that this lack of a difference may have resulted from a floor effect. However, as can be seen in Figure 2, the means for both groups were substantially above the floor value of $0.70 \mathrm{log} \mathrm{sec}$. This floor value is calculated by considering the time that a subject would register if it showed no conditioned suppression to the stimulus. Essentially, if the subjects continue drinking in the presence of the stimulus, they will register 5 cumulative sec of drinking in $5 \mathrm{sec}$. Although no subjects reached this absolute behavioral floor, it may be argued that there was a functional or psychological floor for this particular preparation that was higher than the absolute floor (approaching the mean suppression time of Group Many-LI). The fact that a number of subjects did approach the 5-sec limit (2 from Group Few-LI and 3 from Group Many-LI), registering responses in the range of 5-6 sec, indicates that the functional or psychological floor for this preparation could not be significantly higher than the absolute floor. Furthermore, a dependent samples $t$ test comparing the
pre-CS and CS scores for the subjects in Group Many-LI revealed a marginally significant difference, reflecting slightly lower responding to the initial presentation of the context $(1.00 \log \mathrm{sec})$ than to the CS $(1.12 \log \mathrm{sec})[t(23)=$ $2.05, p=.052]$. Again, this suggests that any functional floor for this preparation lies below the level of responding to the CS observed in Group Many-LI.

\section{GENERAL DISCUSSION}

The present series of experiments demonstrates that the context specificity of the CS preexposure effect can be attenuated if the CS is presented in multiple contexts before conditioning (Experiment 1) or if there are a sufficient number of CS-alone trials (Experiment 2). These observations indicate an empirical similarity between the context specificity of latent inhibition and that of extinction. Although this similarity is not well addressed by most modern theories, it does provide further support for the notion that extinction and latent inhibition may share common underlying cognitive processes. Furthermore, these results provide useful information about the nature of the context specificity of latent inhibition that corresponds to predictions of modern learning theories.

The present series of experiments provides support for some conceptions of the mechanisms underlying latent inhibition. In particular, these data might be best explained by theories that stress the role that the context plays in latent inhibition(e.g., Lubow \& Gewirtz, 1995; McLaren \& Mackintosh, 2000; Miller \& Matzel, 1988; Wagner, 1981). Although these models vary widely in their accounts of latent inhibition, all suggest that the association built between the CS and the context during the preexposure phase of latent inhibition mediates the retardation in responding (either through an acquisition- or responsebased mechanism). For all of these models, latent inhibition is context specific because the CS-context association developed during preexposure will not affect responding if the CS is trained in a different context.

The aforementioned models account for the results of Experiment 1 if the context is assumed to be an elemental stimulus (i.e., a stimulus composed of many individually associable elements), an assumption that is explicit in models such as Wagner's (1981) SOP and McLaren and Mackintosh (2000). In Experiment 1, subjects' receiving partial preexposure in multiple contexts (different from the training context) would allow the CS to be associated with a more diverse number of contextual elements relative to a control that receives all of the preexposures in one context. This increases the chances that a novel training context would share some elements with the preexposure contexts, essentially increasing the similarity between the contexts of preexposure and training. If the novel training context shares enough elements with the preexposure contexts, then the latent inhibition effect should generalize to this context. The observations of Experiment 1 are consistent with this view. 
The results of Experiment 2 can also be predicted by a number of theories emphasizing the importance of context-CS associations in latent inhibition if it is assumed that only a sample of context elements are able to become associated with the US on a given trial. Again, the idea of elemental sampling is explicitly stated in the formal models of Wagner's (1981) SOP and McLaren and Mackintosh (2000), but could easily be applied to many other theories of latent inhibition. If only a percentage of the elements composing the context are able to associate with the CS during a particular CS-alone presentation, then massive preexposure in one context should increase the percentage of contextual elements that will be associated with the CS. Increasing the number of elements sampled in turn increases the probability that some elements of a novel training context will correspond to some elements of the preexposure context. Consistent with this expectation, the results of Experiment 2 indicated that a larger number of preexposure trials can facilitate latent inhibition despite a context shift between preexposure and conditioning.

In addition to the theoretical implications of the present data, there is also a clinical utility. For example, Lubow (1998) details many possible clinical uses for latent inhibition. The latent inhibition effect may be used as a behavioral treatment to prevent maladaptive behaviors from being acquired or expressed, just as an extinction treatment is used to eliminate unwanted behaviors after they have been acquired. Consequently, the context specificity of latent inhibition could be an obstacle for potential prophylactic treatments because it causes the prevention of maladaptive behaviors to be context specific. The results of the present series of experiments suggest that certain techniques may enhance the context generalization of latent inhibition training. Although the results of Experiment 2 may be obvious from a clinical standpoint (more treatment yields a more effective treatment), the results of Experiment 1 suggest a less obvious but potentially useful technique for establishing effective latent inhibition. One possible clinical application for the present series involves the prevention of conditioned taste aversion learning. Cancer patients that receive chemotherapy treatments often develop conditioned aversions to the food that they eat close to the time of treatment, which potentially enhances the wasting effects of the treatments and slows recovery. Possibly, preexposure to a food stimulus in multiple contexts could best prevent the expression of a conditioned taste aversion outside of the context in which it is learned.

Also reviewed by Lubow (1998), another potential application of these data regards the prophylactic treatment of phobias. Human research indicates that prophylactic systematic desensitization can retard phobic responses to common fear-inducing stimuli such as snakes or public speaking (Jaremko, 1978; Jaremko \& Wenrich, 1973). The present results are especially pertinent to this potential application, because the context of anxiety-inducing stimuli can be extremely variable. For example, a phobia to a common animal such as a dog could manifest in many different contexts, and any prophylactic treatment of these phobias would be ineffective if that treatment were highly context specific. However, in considering this possible clinical application, it is important to note that the acquisition or expression of human phobias and anxiety disorders may not be directly analogous to fear conditioning (for a review of criticisms and rebuttals, see Ayres, 1998). Although it is possible that most phobias are not learned in a traditional Pavlovian method, the potential context specificity of a proactive fear-reducing treatment such as prophylactic systematic desensitization could still be an issue. The manipulations included in the present designs (i.e., CS preexposure in multiple contexts and massive CS preexposure) increase the contextual generality of the prophylactic fear-retarding effects of latent inhibition.

In summary, the results of this series of experiments further demonstrate the empirical similarities between the effects of latent inhibition and extinction, suggesting that the context plays a similar role in these two phenomena. However, these empirical similarities do not necessarily indicate that similar cognitive or physiological mechanisms underlie latent inhibition and extinction. For example, the comparator hypothesis (Miller \& Matzel, 1988) proposes that similar mechanisms influence latent inhibition and extinction, whereas Wagner's (1981) SOP model explains the two effects using very different mechanisms. Biologically, there is evidence for a dissociation of the physiological substrates underlying latent inhibition and extinction in fear conditioning, particularly with regard to context specificity (e.g., Harris \& Westbrook, 1998). Regardless of the implications for mechanisms, there is a potential clinical application for the results. The generalization of prophylactic behavioral treatments may be increased through extensive training or through training in multiple contexts. Using either of these techniques could augment the overall effectiveness of latent inhibition as a treatment to prevent the development of maladaptive behaviors.

\section{REFERENCES}

Aguado, L., Symonds, M., \& Hall, G. (1994). Interval between preexposure and test determines the magnitude of latent inhibition: Implications for an interference account. Animal Learning \& Behavior, 22, 188-194

AYres, J. J. B. (1998). Fear conditioning and avoidance. In W. O'Donahue (Ed.), Learning and behavior therapy (pp. 122-145). Boston: Allyn \& Bacon.

Bouton, M. E. (1993). Context, time, and memory retrieval in the interference paradigms of Pavlovian learning. Psychological Bulletin, 114, 80-99.

Bouton, M. E., \& Bolles, R. C. (1979). Contextual control of the extinction of conditioned fear. Learning \& Motivation, 10, 445-466.

Bouton, M. E., \& KIng, D. A. (1983). Contextual control of the extinction of conditioned fear: Tests for the associative value of the context. Journal of Experimental Psychology: Animal Behavioral Processes, 9, 248-265.

Bouton, M. E., \& Ricker, S. T. (1994). Renewal of extinguished responding in a second context. Animal Learning \& Behavior, 22, 317 324. 
De la CAsa, L. G., \& Lubow, R. E. (2000). Super-latent inhibition with delayed conditioned taste aversion testing. Animal Learning \& Behavior, 28, 389-399.

De la CASA, L. G., \& Lubow, R. E. (2002). An empirical analysis of the super-latent inhibition effect. Animal Learning \& Behavior, 30, 112 120.

Denniston, J. C., Chang, R. C., \& Miller, R. R. (2003). Massive extinction treatment attenuates the renewal effect. Learning \& Motivation, 34, 68-86.

Grahame, N. J., Barnet, R. C., Gunther, L. M., \& Miller, R. R. (1994) Latent inhibition as a performance deficit resulting from CS-context associations. Animal Learning \& Behavior, 22, 395-408.

Gunther, L. M., Denniston, J. C., \& Miller, R. R. (1998). Conducting exposure treatment in multiple contexts can prevent relapse. $B e$ haviour Research \& Therapy, 36, 75-91.

Hall, G., \& Channell, S. (1983). Contextual effects in latent inhibition with an appetitive conditioning procedure. Animal Learning \& Behavior, 11, 67-74.

Harris, J. A., \& Westbrook, R. F. (1998). Evidence that GABA transmission mediates context specific extinction of learned fear. Psychopharmacology, 140, 105-115.

JAREMKo, M. E. (1978). Prophylactic desensitization: An analogue test. Journal of Behavioral Therapy and Experimental Psychiatry, 9, 5-9.

JAREMKo, M. E., \& WENRICH, W. W. (1973). A prophylactic usage of systematic desensitization. Journal of Behavioral Therapy \& Experimental Psychiatry, 4, 103-105.

Killcross, A. S., Kiernan, M. J., Dwyer, D., \& Westbrook, R. F. (1998). Effects of retention interval on latent inhibition and perceptual learning Ouarterly Journal of Experimental Psychology, 51B, 59-74.

Kraemer, P. J., Randall, C. K., \& CARbary, T. J. (1991). Release from latent inhibition with delayed testing. Animal Learning \& Behavior, 19, 139-145.

Lovibond, P. F., Preston, G. C., \& Mackintosh, N. J. (1984). Contex specificity of conditioning, extinction, and latent inhibition. Journal of Experimental Psychology: Animal Behavioral Processes, 10, 360-375

LuBow, R. E. (1998). Latent inhibition and behavioral pathology: Prophylactic and other possible effects of stimulus preexposure. In W. O'Donahue (Ed.), Learning and behavior therapy (pp. 107-121). Boston: Allyn \& Bacon.
Lubow, R. E., \& Gewirtz, J. C. (1995). Latent inhibition in humans: Data, theory, and implications for schizophrenia. Psychological Bulletin, 117, 87-103.

Lubow, R. E., \& Moore, A. U. (1959). Latent inhibition: The effect of nonreinforced pre-exposure to the conditional stimulus. Journal of Comparative \& Physiological Psychology, 52, 415-419.

Lubow, R. E., Schnur, P., \& Rifkin, B. (1976). Latent inhibition and conditioned attention theory. Journal of Experimental Psychology: Animal Behavioral Processes, 2, 163-174.

Mclaren, I. P. L., Bennett, C., Plaisted, K., Aitken, M., \& MackINTOSH, N. J. (1994). Latent inhibition, context specificity, and context familiarity. Quarterly Journal of Experimental Psychology, 47B, 387-400.

McLaren, I. P. L., \& Mackintosh, N. J. (2000). An elemental model of associative learning: I. Latent inhibition and perceptual learning. Animal Learning \& Behavior, 28, 211-246.

Miller, R. R., \& Matzel, L. D. (1988). The comparator hypothesis: A response rule for the expression of associations. In G. H. Bower (Ed.), The psychology of learning and motivation (Vol. 22, pp. 51-92). San Diego: Academic Press.

Pavlov, I. P. (1927). Conditioned reflexes (G. V. Anrep, Trans.). London: Oxford University Press.

Pearce, J. M., \& Hall, G. (1980). A model for Pavlovian learning: Variations in the effectiveness of conditioned but not of unconditioned stimuli. Psychological Review, 87, 532-552.

Rescorla, R. A., \& Wagner, A. R. (1972). A theory of Pavlovian conditioning: Variations in the effectiveness of reinforcement and nonreinforcement. In A. H. Black \& W. F. Prokasky (Eds.), Classical conditioning II: Current research and theory (pp. 64-99). New York: Appleton-Century-Crofts.

WAGNER, A. R. (1981). SOP: A model of automatic memory processing in animal behavior. In N. E. Spear \& R. R. Miller (Eds.), Information processing in animals: Memory mechanisms (pp.5-47). Hillsdale, NJ: Erlbaum.

(Manuscript received September 30, 2002; revision accepted for publication June 27, 2003.) 